\title{
Analysis of the causes of pathological patterns of the kinematic locomotor profile based on the findings of computer gait analysis in children with spastic CP types
}

\author{
G.M. Chibirov, T.I. Dolganova, D.V. Dolganov, D.A. Popkov
}

Russian Ilizarov Scientific Centre for Restorative Traumatology and Orthopaedics, Kurgan, Russian Federation

To interpret the clinical gait analysis (CGA), it is necessary to associate changes in gait with clinical impairment and differentiate the primary deviations in the gait stereotype from compensatory adaptive changes. Purpose To assess the pathological elements of the locomotor profile according to video gait analysis and clinical examination of patients; to compare the abnormalities identified in gait kinematics with the probable clinical causes of these abnormalities. Materials and methods Clinical examination and assessment of the locomotor profile with video gait analysis (CGA) were performed in 46 children (92 limbs) with bilateral spastic types of cerebral palsy (25 boys, 21 girls). We used 6 Qualisys Oqus cameras and one AMTI dynamometric platform (Advanced Mechanical Technology Inc., Watertown, MA, USA) with passive marker video capture technology. The IOR model was used for installing markers. The patterns of the locomotor profile adopted by the Delphic Convention were analyzed. The assessment of diagnostic coincidences or discrepancies was evaluated as percentage rates. Results The portion of the pathological elements of the locomotor profile identified according to the video gait analysis and clinical examination of patients is presented in the tables. The positive ratio of the pathological elements of the locomotor profile identified according to the video gait analysis and clinical examination of patients averaged $66.7 \%$. The lowest error rate: when assessing the limitation of the range of motion of the ankle joint and hip joint there were $82.6 \%$ and $81.8 \%$ of positive results, respectively. Discussion Clinical gait analysis (CGA) is crucial in controversial situations regarding detorsion osteotomies in multilevel operations. Conclusions Muscle retraction is the main (primary) clinical sign leading to positional kinematic deviations in joints and segments. The limitation of the range of motion in the knee and ankle joints due to muscle retraction results in secondary contractures of these joints.

Keywords: cerebral palsy, clinical gait analysis

Video gait analysis and criteria of the Edinburgh Gait Assessment are research methods in the diagnosis of gait disorders [1], operative orthopedic interventions planning and rehabilitation of patients with cerebral palsy. They provide quantification of the disorders detected and monitoring of the rehabilitation efficiency [2, 3, 4, 5]. But the objective "gold" standard in the diagnosis of functional disorders of the musculoskeletal system is a computer instrumental study of walking biomechanics, Clinical Gait Analysis (CGA), which enables to quantify the disorders [6] for planning a multi-level surgery in this group of patients $[7,8,9]$.
Changes in the locomotor profile in cerebral palsy combine a large number of diverse deviations rather than clearly observed types. To interpret CGA, it is necessary to associate changes in gait with clinical impairments and to differentiate primary deviations in the stereotype of gait from compensatory adaptive changes.

The aim of the study was to assess the pathological elements of the locomotor profile identified in video gait analysis and clinical examination of patients; compare abnormalities in gait kinematics observed in a particular joint/segment with possible clinical causes of such deviations.

\section{MATERIALS AND METHODS}

Clinical examination and assessment of the locomotor profile with video gait analysis were performed in 46 children (92 limbs) with bilateral spastic types of cerebral palsy ( 25 boys and 21 girls). The mean age at the time of the analysis was 11.9 (range, 5-18) years. All patients had previous surgical interventions. The level of motor disorders was determined in accordance with the classification of global motor functions (GMFCS) [10]. There were five children of Level I, 31 patients with Level II and ten with Level III.

Gait analysis included physical examination (muscle strength and selective motor control, spasticity, range of joint motion and rotational alignment of the lower extremities), video recording in the frontal and sagittal planes, as well as three-

Chibirov G.M., Dolganova T.I., Dolganov D.V., Popkov D.A. Analysis of the causes of pathological patterns of the kinematic locomotor profile based on the findings of computer gait analysis in children with spastic CP types. Genij Ortopedii, 2019, vol. 25, no 4, pp. 493-500. DOI 10.18019/1028-4427-2019-25-4-493-500. (In Russian) 
dimensional kinematics. The scientific laboratory of the Clinic for Neuroorthopedics and Systemic Diseases (Ilizarov Gait Analysis Laboratory) has six Qualisys Oqus cameras and one dynamometric AMTI platform (Advanced Mechanical Technology Inc., Watertown, MA, USA) to study the kinematics and kinetics of patient's movements with video capture of passive markers. Children walked barefoot; if necessary, helped by holding their hands for support, with the speed they were used to on a 7-meter track. The IOR model was used for markers, [11], which is optimal with a minimal system configuration, suitable for walking analysis if patient's speed is low to decrease artefacts of skin motion [12].

The work analyses the locomotor profile patterns adopted by the Delphi consensus [13, 14, 15]: ankle joint kinematics in horizontal (Fig. 1) and sagittal planes (Fig. 2); knee joint kinematics in the sagittal plane (Fig. 3), frontal (Fig. 4) and horizontal planes (Fig. 5), hip joint kinematics in the sagittal, frontal and horizontal planes (Fig. 6), kinematics of the pelvis in the sagittal (Fig. 7), horizontal and frontal planes (Fig. 8).
Foot Progression (Int +ve)

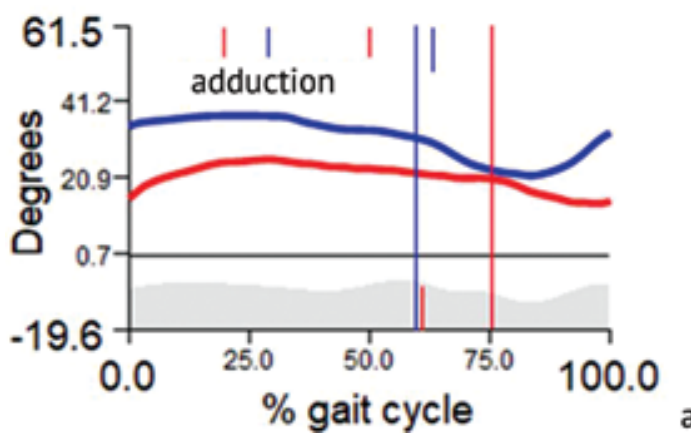

Foot Progression (Int +ve)

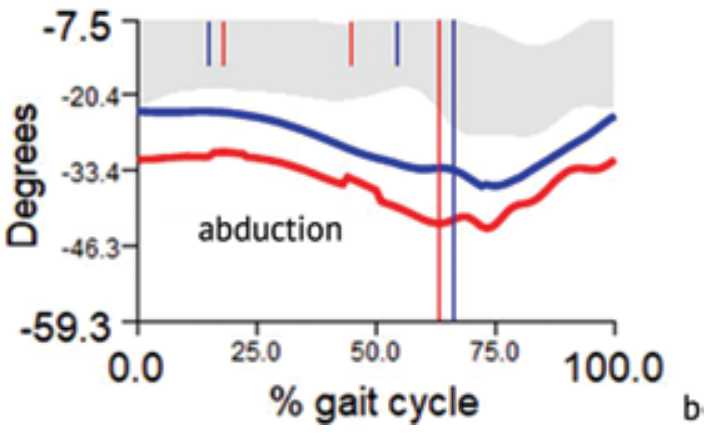

Fig. 1 Example of ankle joint kinematics in the horizontal plane; $\boldsymbol{a}$ patient K., 11 years old, cerebral palsy, spastic diplegia, GMFCS level II: right and left foot in adduction in the support and non-support gait cycle; $\boldsymbol{b}$ patient P., 12 years old, cerebral palsy, spastic diplegia, GMFCS level II: right and left foot in abduction in the support and non-support gait cycle

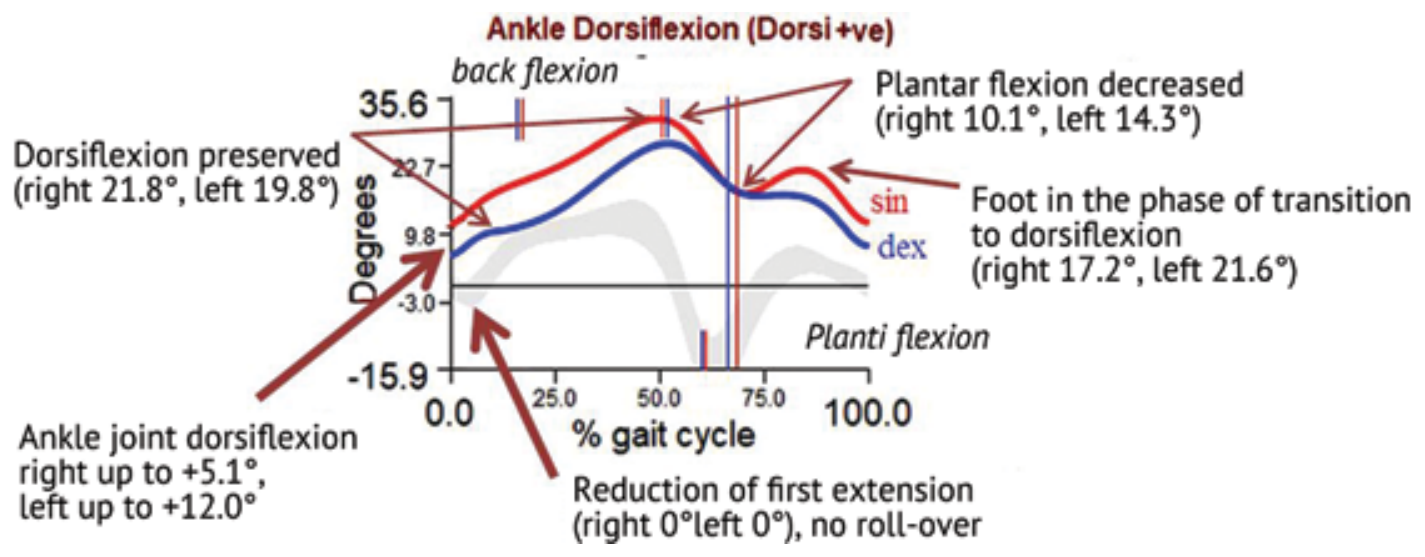

Fig. 2 Example of ankle joint kinematics in the sagittal plane of patient R., 11 years old, cerebral palsy, spastic diplegia, GMFCS level II: right and left foot in dorsiflexion in the support and non-support gait cycle

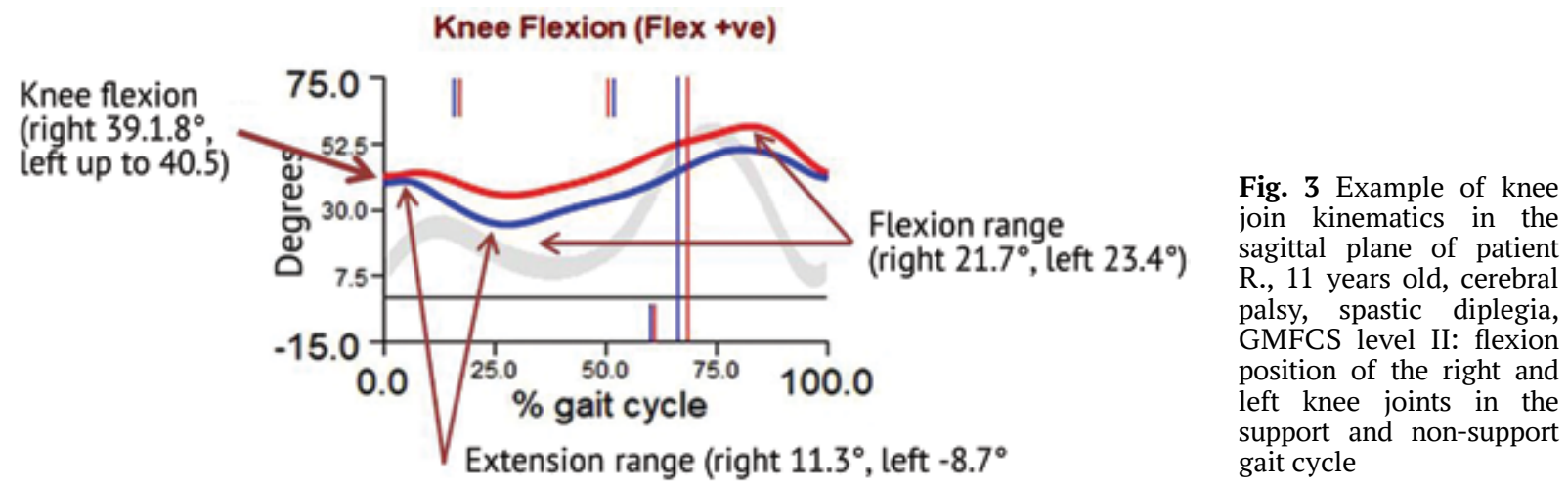




\section{Knee Rotation (Int +ve)}

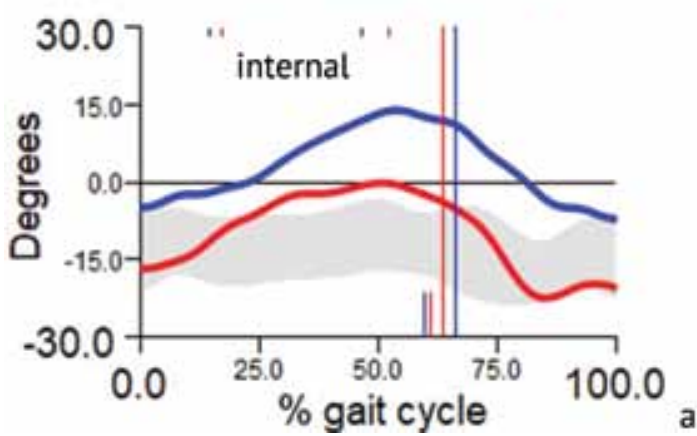

Knee Rotation (Int +ve)

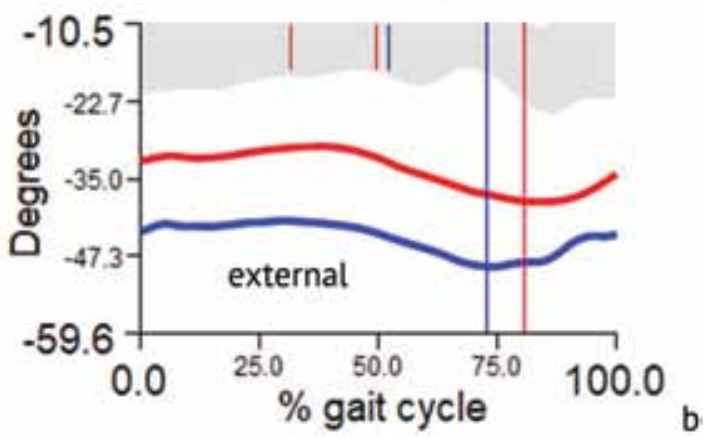

Fig. 4 Example of knee joint kinematics in the horizontal plane: $\boldsymbol{a}$ patient S., 11 years old, cerebral palsy, spastic diplegia, GMFCS level II: right knee joint in the position of the internal torsion in the support phase of the gait cycle; $\boldsymbol{b}$ patient T., 15 years old, cerebral palsy, spastic diplegia, GMFCS level III: right and left knee in the position of the external rotation in the support and non-support phase of the gait cycle

Knee Adduction (Add +ve)

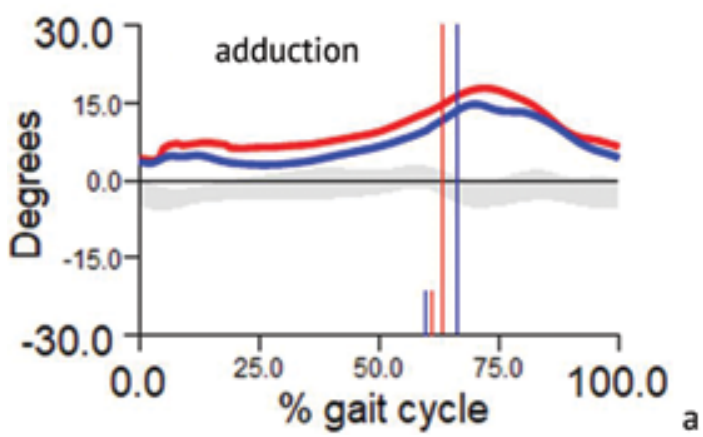

Knee Adduction (Add +ve)

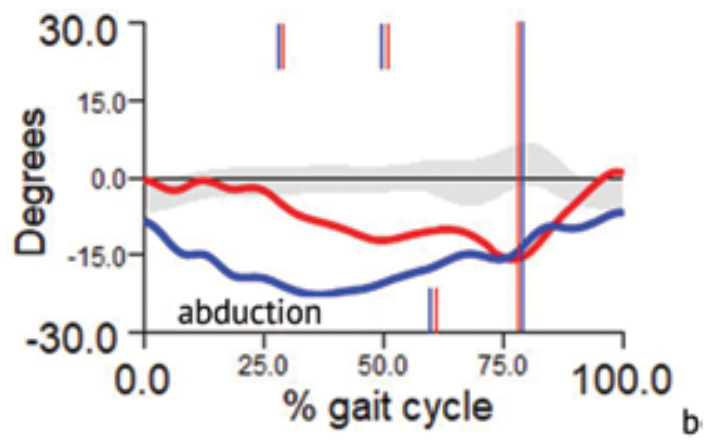

Fig. 5 Example of knee joint kinematics in the frontal plane: $\boldsymbol{a}$ patient R., 10 years old, cerebral palsy, spastic diplegia, GMFCS level II: right and left lower legs in adduction in the support and non-support phases of the gait cycles; $\boldsymbol{b}$ patient M., 15 years old, cerebral palsy, spastic diplegia, GMFCS level III: right and left lower legs in abduction in the support and non-support phases of the gait cycle
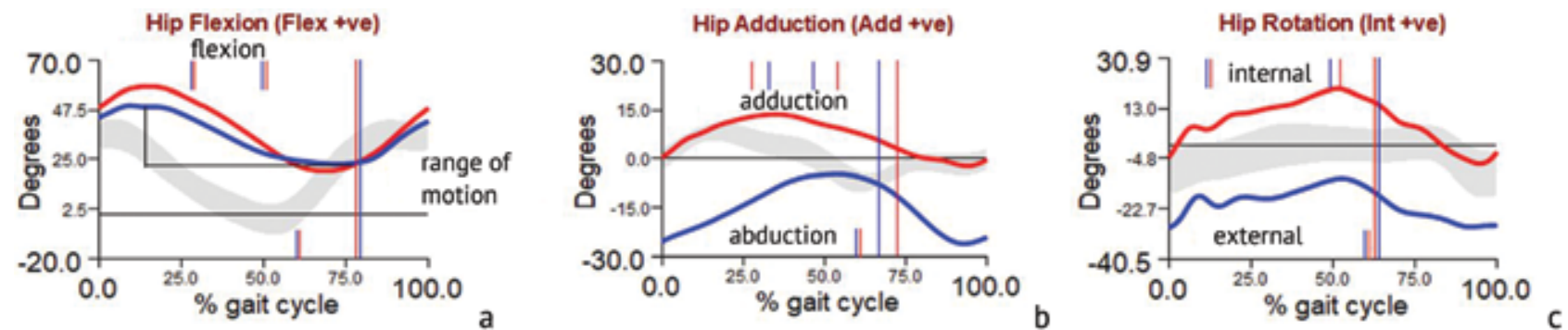

Fig. 6 Example of hip joint kinematics; $\boldsymbol{a}$ patient B., 10 years old, cerebral palsy, spastic diplegia, GMFCS level II (in the sagittal plane): flexion of the right and left femur; $\boldsymbol{b}$ patient R., 11 years old, cerebral palsy, spastic diplegia, GMFCS level III (in the frontal plane), on the left - femur in the adduction position, no femur abduction, on the right - femur in the abduction in the support and non-support phase of the gait cycle; c patient K., 12 years old, cerebral palsy, spastic diplegia, GMFCS level II (in the horizontal plane), on the right is the external rotation of the femur, on the left is internal rotation of the femur

Pelvic Tilt (Ant +ve)

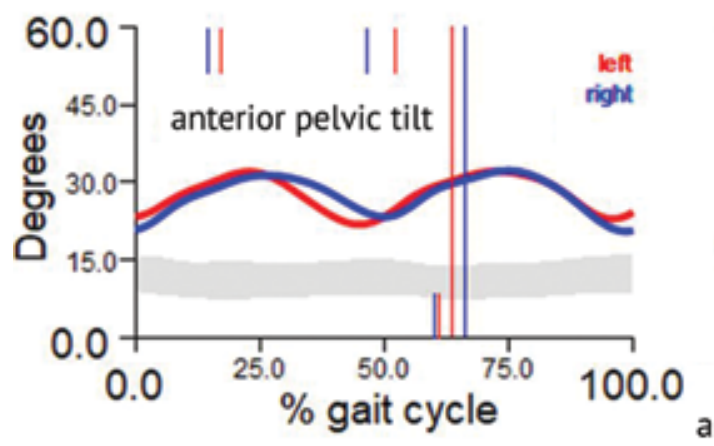

Pelvic Tilt (Ant +ve)

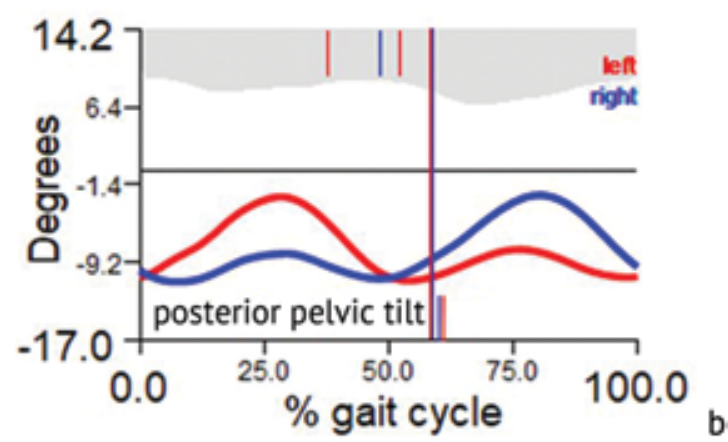

Fig. 7 Example of the kinematics of the pelvis in the sagittal plane: $\boldsymbol{a}$ patient S., 15 years old, cerebral palsy, spastic diplegia, GMFCS level II: anterior inclination of the pelvis; $\boldsymbol{b}$ patient H., 10 years old, cerebral palsy, spastic diplegia, GMFCS level III: posterior pelvic tilt 
Pelvic Obliquity (Up +ve)

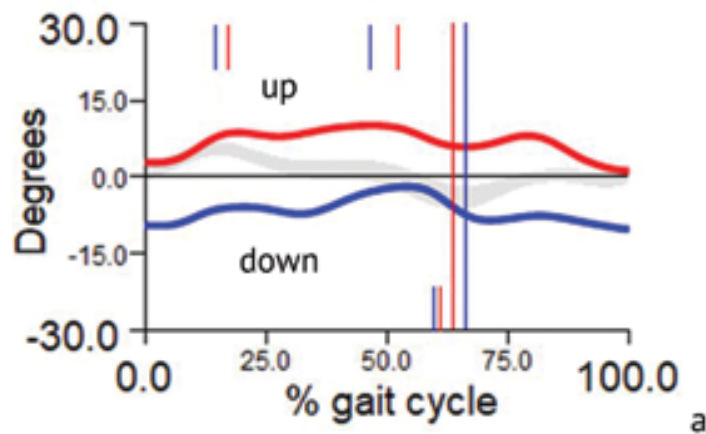

Pelvic Rotation (Int +ve)

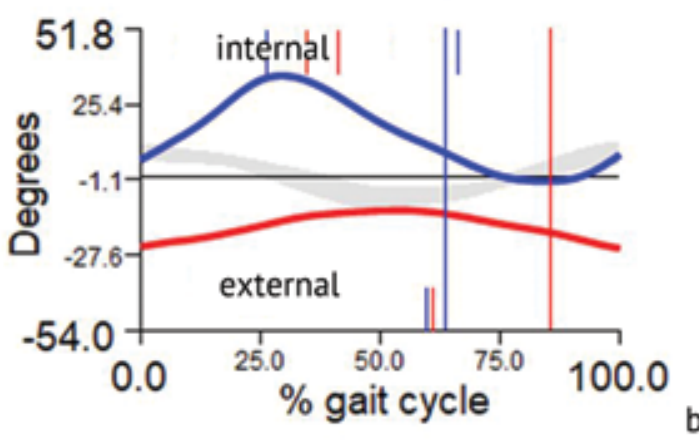

Fig. 8 Example of the kinematics of the pelvis: $\boldsymbol{a}$ patient B., 15 years old, cerebral palsy, spastic diplegia, GMFCS level II (in the frontal plane): obliquity of the pelvis from right downwards due to a shortened right lower limb; $\boldsymbol{b}$ patient F., 11 years old, cerebral palsy, spastic diplegia, GMFCS level II (in the horizontal plane): rotation of the pelvis inwards on the right

Results were considered positive when the findings of the clinical diagnosis coincided with the data of video analysis, and were negative when the video analysis revealed pathological elements that were not clinically observed, and, conversely, when the clinical findings were not confirmed by video analysis. Diagnostic coincidences or discrepancies were expressed in percent.

The research was approved by the ethics committee at the Federal State Budgetary Institution Russian Ilizarov Scientific Center RTO. All patients participating in the study signed an informed consent to be included into this study and publish the results of their study without identification.

\section{RESULTS}

Pathological elements of the locomotor profile identified according to video gait analysis and clinical examination of patients and their percentage is presented

in Table 1. The results of deviations in gait kinematics observed in a separate joint/segment and clinical causes that provoked them are presented in Tables 2, 3, 4, and 5 .

Table 1

Percentage of identified pathological elements of the locomotor profile according to video gait analysis and clinical examination of patients

\begin{tabular}{|c|c|c|c|}
\hline \multirow{3}{*}{$\begin{array}{c}\text { Elements of the locomotor profile } \\
\text { ( } \mathrm{n}-\text { total number of joints/segments analysed) }\end{array}$} & \multirow[b]{2}{*}{$\begin{array}{l}\text { Positive } \\
\text { results }\end{array}$} & \multicolumn{2}{|c|}{ Negative results } \\
\hline & & $\begin{array}{l}\text { Video analysis not } \\
\text { confirmed clinically }\end{array}$ & $\begin{array}{l}\text { Clinical signs not confirmed } \\
\text { with video analysis }\end{array}$ \\
\hline & \multicolumn{3}{|c|}{$\mathrm{n}-$ number of cases detected } \\
\hline Foot abduction/adduction in support phase $(\mathrm{n}=92)$ & $67(72.8 \%)$ & $23(25.0 \%)$ & $2(2.2 \%)$ \\
\hline Foot dorsiflexion in support phase $(\mathrm{n}=57)$ & $37(64.9 \%)$ & $18(33.5 \%)$ & $2(1.6 \%)$ \\
\hline Foot plantiflexion in support phase $(n=35)$ & $27(77.1 \%)$ & $6(17.1 \%)$ & $2(5.7 \%)$ \\
\hline \multicolumn{4}{|l|}{ Change in the ankle joint motion range: } \\
\hline Reduction in plantar flexion $(8-10 \%$ of gait cycle $)(n=92)$ & $67(72.8 \%)$ & $20(21.7 \%)$ & $5(5.5 \%)$ \\
\hline Low range dorsiflexion $(10-55 \%$ of GC) $(n=77)$ & $39(50.6 \%)$ & $8(14.0 \%)$ & $30(35.4 \%)$ \\
\hline Restriction of the range of motion $(55-70 \%$ GC $(n=92)$ & $76(82.6 \%)$ & $16(17.4 \%)$ & \\
\hline \multicolumn{4}{|l|}{ Foot position in non-support phase: } \\
\hline Dorsiflexion $(n=67)$ & $34(50.7 \%)$ & $29(43.3 \%)$ & $4(6.0 \%)$ \\
\hline Plantiflexion $(\mathrm{n}=16)$ & $10(62.5 \%)$ & $1(6.2 \%)$ & $5(31.3 \%)$ \\
\hline Knee joint flexion (15-25 \% GC) $(n=83)$ & $47(55.5 \%)$ & $31(38.8 \%)$ & $5(5.7 \%)$ \\
\hline Limited knee extension (25-45 \% GC) $(n=75)$ & $55(73.3 \%)$ & $13(17.3 \%)$ & $7(9.4 \%)$ \\
\hline Limited knee flexion (45-70 \% GC) $(\mathrm{n}=59)$ & $39(66.1 \%)$ & $16(27.1 \%)$ & $4(6.8 \%)$ \\
\hline $\begin{array}{l}\text { Torsion of the knee joint (externa/internal rotation) in support } \\
\text { phase }(\mathrm{n}=85)\end{array}$ & $49(57.6 \%)$ & $17(20.0 \%)$ & $19(22.4 \%)$ \\
\hline Lower leg in abduction/adduction (support phase of GC) $(\mathrm{n}=31)$ & $20(64.5 \%)$ & $11(35.6 \%)$ & \\
\hline Flexion of femur $(8-10 \%$ GC) $(n=77)$ & $43(55.5 \%)$ & $25(33.3 \%)$ & $9(11.2 \%)$ \\
\hline Restriction of range of motion in hip joint (55\% -95\% GC (n = 11) & $9(81.8 \%)$ & $2(18.2 \%)$ & \\
\hline $\begin{array}{l}\text { Femur in abduction/adduction relative pelvis (in support phase } \\
\text { of GC) }(n=92)\end{array}$ & $67(72.8 \%)$ & $25(27.2 \%)$ & \\
\hline Femur torsion external/internal $(\mathrm{n}=72)$ & $44(61.1 \%)$ & $21(29.2 \%)$ & $7(9.7 \%)$ \\
\hline Pelvis position in the sagittal plane forward/backward $(n=46)$ & $34(73.9 \%)$ & $10(21.7 \%)$ & $2(4.4 \%)$ \\
\hline Pelvis tilt in the frontal plane (upward/doownward) $(\mathrm{n}=46)$ & $36(78.3 \%)$ & $10(21.7 \%)$ & \\
\hline $\begin{array}{l}\text { Pelvis position in the horizontal plane - internal/external } \\
\text { rotation }(\mathrm{n}=46)\end{array}$ & $26(56.5 \%)$ & $15(32.6 \%)$ & $5(10.9 \%)$ \\
\hline
\end{tabular}


Table 2

Clinical signs in kinematic deviations in the hip joint ( $\mathrm{n}$ - total number of joints/segments analysed; \% in the sample)

\begin{tabular}{|l|l|c|}
\hline \multicolumn{1}{|c|}{ Type of motion in joint/segment } & \multicolumn{1}{|c|}{ Associated clinical signs } & Number of cases, \% \\
\hline \multirow{3}{*}{ Flexion position of the femur $(\mathrm{n}=77)$} & Retraction of m. iliopsoas & $19(24.7 \%)$ \\
\cline { 2 - 3 } & Retraction of m. rectus femoris & $54(70.1 \%)$ \\
\cline { 2 - 3 } & Femur subluxation & $4(5.2 \%)$ \\
\hline Femur adduction $(\mathrm{n}=19)$ & Retraction of femoral adductors & $19(100 \%)$ \\
\hline Femur abduction $(\mathrm{n}=48)$ & Presumably, compensatory position of the lower limbs & $48(100 \%)$ \\
\hline \multirow{2}{*}{ External rotation of the femur $(\mathrm{n}=21)$} & Retroversion of the femoral neck & $4(19 \%)$ \\
\cline { 2 - 3 } & Retraction of external rotators & $17(81 \%)$ \\
\hline \multirow{2}{*}{ Internal rotation of the femur $(\mathrm{n}=51)$} & Anteversion of the femoral neck & $37(27.5 \%)$ \\
\cline { 2 - 3 } & Retraction of internal rotators & $37(72.5 \%)$ \\
\hline
\end{tabular}

Table 3

Clinical signs in kinematic deviations in the knee joint ( $n$ - total number of joints/segments analysed; \% in the sample)

\begin{tabular}{|l|l|c|}
\hline \multicolumn{1}{|c|}{ Type of motion in joint/segment } & \multicolumn{1}{|c|}{ Associated clinical signs } & Number of cases, \% \\
\hline \multirow{2}{*}{ Knee flexion $(\mathrm{n}=47)$} & Retraction of knee flexors, including high vertebra & $40(85.1 \%)$ \\
\cline { 2 - 3 } & Flexion contracture of the hip joint & $7(14.9 \%)$ \\
\hline $\begin{array}{l}\text { Restriction of the range of motion } \\
\text { in the knee joint }(\mathrm{n}=59)\end{array}$ & Contracture of the knee joint & $56(94.9 \%)$ \\
\cline { 2 - 3 } $\begin{array}{l}\text { External rotation of the knee joint } \\
(\mathrm{n}=45)\end{array}$ & Stiff knee gait & $25(5.1 \%)$ \\
\hline \multirow{2}{*}{$\begin{array}{l}\text { Internal rotation of the knee joint } \\
(\mathrm{n}=40)\end{array}$} & Tontracture of the hip joint & $20(44.5 \%)$ \\
\hline \multirow{2}{*}{ Lower leg abduction $(\mathrm{n}=31)$} & Excessive anteversion of the femoral neck & $17(42.5 \%)$ \\
\cline { 2 - 3 } & Retraction of m. gracilis & $23(57.5 \%)$ \\
\hline \multirow{2}{*}{ Lower leg adduction $(\mathrm{n}=11)$} & Excessive anteversion of the femoral neck & $12(38.7 \%)$ \\
\cline { 2 - 3 } & Valgus deformity of the lower limbs & $19(61.3 \%)$ \\
\hline
\end{tabular}

Table 4

Clinical signs in kinematic deviations in the pelvis by walking

( $\mathrm{n}$ - total number of joints/segments analysed; \% in the sample)

\begin{tabular}{|l|l|c|}
\hline \multicolumn{1}{|c|}{ Type of motion in joint/segment } & \multicolumn{1}{|c|}{ Associated clinical signs } & Number of cases, \% \\
\hline \multirow{2}{*}{ Pelvis inclination forward $(\mathrm{n}=30)$} & Retraction of m. iliopsoas & $23(77.6 \%)$ \\
\cline { 2 - 3 } $\begin{array}{l}\text { Increase in the range of motion of the } \\
\text { pelvis in the sagittal plane }(\mathrm{n}=24)\end{array}$ & Retraction of m. rectus femoris & $22(92.4 \%)$ \\
\cline { 2 - 3 } Pelvic tilt in the frontal plane $(\mathrm{n}=38)$ & Subluxation of the femur & $2(8.4 \%)$ \\
\cline { 2 - 3 } & $\begin{array}{l}\text { Lower limb shortening } \\
\text { Persistent adduction contracture of the hip joint and }\end{array}$ & $25(65.7 \%)$ \\
\hline Rotation of the pelvis $(\mathrm{n}=27)$ & $\begin{array}{l}\text { In hemiparesis - a consequence of the internal } \\
\text { rotation of the contrainvolved limb }\end{array}$ & $27(100 \%)$ \\
\hline
\end{tabular}

Table 5

Clinical signs in kinematic abnormalities in the ankle and foot

( $n$ - total number of joints / segments analyzed; part in the sample, \%)

\begin{tabular}{|l|l|c|}
\hline \multicolumn{1}{|c|}{ Type of motion in joint/segment } & \multicolumn{1}{|c|}{ Associated clinical signs } & Number of cases, \% \\
\hline Varus deformity of the foot $(\mathrm{n}=4)$ & Retraction of the anterior, posterior tibial muscle & $4(100 \%)$ \\
\hline \multirow{2}{*}{ Valgus deformity of the foot $(\mathrm{n}=19)$} & Previous operations & $3(15.7 \%)$ \\
\cline { 2 - 3 } & Contractures of the lower limb joints & $16(84.3 \%)$ \\
\hline \multirow{2}{*}{ Foot position in abduction $(\mathrm{n}=50)$} & Foot deformity & $25(100 \%)$ \\
\cline { 2 - 3 } Foot position in adduction $(\mathrm{n}=42)$ & Contracture of the knee joint & $37(88.1 \%)$ \\
\hline \multirow{2}{*}{ Flexion position of the foot $(\mathrm{n}=59)$} & Foot deformity & $5(11.9 \%)$ \\
\cline { 2 - 3 } & Internal rotation of the femur & $21(35.5 \%)$ \\
\cline { 2 - 3 } & Retraction of the dorsal flexors of the foot & $38(64.5 \%)$ \\
\hline Extension position of the foot $(\mathrm{n}=6)$ & Reak tonus of the plantar flexors of the foot (after Ulzibat) & $6(100 \%)$ \\
\hline \multirow{2}{*}{$\begin{array}{l}\text { Reduction in the plantar bending } \\
(\mathrm{n}=86)\end{array}$} & Pronounced flexion contracture of the knee joint & $72(83.7 \%)$ \\
\cline { 2 - 3 } & $\begin{array}{l}\text { Foot deformity in combination with the retraction of } \\
\text { the plantar flexors of the foot }\end{array}$ & $86(100 \%)$ \\
\hline
\end{tabular}


Positive results of the correlations of the pathological locomotor profile elements identified according to video gait analysis and clinical examination of patients averaged $66.5 \%$ of cases. Negative results, when the pathological gait element was detected with the CGA method but was not clinically observed, were $25 \%$ of cases; and a clinical symptom, not confirmed by computer video analysis, was $8.4 \%$ of cases (Table 1 ). Discrepancies in foot position evaluation (abduction/ adduction position, dorsal/plantar flexion) according to the clinical examination and CGA averaged $28.4 \%$ of cases; $88 \%$ of them are cases not detected during clinical examination. The largest number of negative results in the assessment of dorsiflexion (18 out of 20 cases) was revealed only quantitatively with the CGA method (Table 1). Varus foot deformity in all patients was due to retraction of the posterior and anterior tibial muscles, and valgus deformity of the foot was mainly observed in contractures of the joints of the lower extremities (84.3\% of cases) (Table 5). Foot deformity combined with muscle retraction clinically dominates in all foot position disorders and plantar flexion reduction. For ankle joint motion, the largest number of errors was overdiagnosis as $35 \%$ of the clinical data were not confirmed by a quantitative CGA. The contracture of the knee joint was a determining factor in limiting the range of its motion ( $94.9 \%$ of cases), and clinically the gait of the "frozen knee" (stiff knee gait) was found in $5 \%$ of cases (Table 3 ). Flexion position in the knee and hip joints in 39 and $33 \%$ of cases, respectively, was not clinically observed. In $85 \%$ of cases, the flexion position of the knee joint in the support phase of the gait cycle was due to retraction of the flexors with a high position of the patella (Table 3). Initial clinical examination did not found restriction of knee joint extension in $23 \%$ of cases. A positive result in the orientation of the knee in the horizontal plane was just over half of the observations, $57.6 \%$. In the group with a negative result, the ratio of CGA data that were not found clinically or were unconfirmed was approximately the same: 9,17 , and 19 , respectively. With the CGA method alone, adduction or abduction of the femur was found in $27 \%$. The femur position in the abduction position was accompanied by retraction of the adductor muscles in $100 \%$ of cases, while femur abduction was due to a compensatory lower limb position in $100 \%$ (Table 2). When evaluating the anterior pelvicc tilt, the error rate was the greatest; a positive result was only in $24 \%$ of cases; in $66 \%$ of cases, the change in the pelvicc tilt was not observed clinically. Pelvis inclination forward was accompanied by retraction of musculus iliopsoas in $77.6 \%$ of cases (Table 4). A positive result was $83 \%$ if the pelvis was tilted backwards. An increase in the pelvis range of motion in the sagittal, frontal and horizontal planes was not clinically observed in 52, 70 and $57 \%$, respectively. It was defined by contracture of the hip joint in $91.6 \%$ of cases and by shortening of the lower limb in $65.7 \%$.

\section{DISCUSSION}

According to the literature, the method of Clinical Gait Analysis (CGA) has a significant impact on orthopedic decision-making $[16,17,18]$ and modifies surgical planning in more than half of cases $[19,20$, 21 ], revealing clinically significant differences in the quality of threshold values [22]. When CGA data are used for planning the operations, early relapses (up to 21 months after surgery) were reported in $15 \%$ of cases. On the contrary, they are $44 \%$ of recurrence in the patients who underwent surgery without performing the CGA [23]. Our results are consistent with the literature. CGA is crucial in controversial situations such as detorsion osteotomies in multilevel operations in young children [24]. Such interventions should not only achieve normal anatomical parameters, but also create the conditions for rehabilitation, in particular, postural management, which is extremely important for the normal development of hip joints and prevention of hip subluxation and dislocation recurrence in children [25].

The literature reports that the analysis of the correlation of positive and negative results of the tests that compare clinical diagnosis and video analysis was characterized by significant variability. The average of matches for all joints was $76 \%$ per doctor while the percentage of correlation ranged from 73 to $90 \%$ for highly qualified doctors and for beginners from 59 to $89 \%$ [26]. According to Rodda J.M. and Stott N.S. similar values were obtained $(66-100 \%$ and $50-$ $68 \%$ of correlation with video analysis, respectively) [27, 28]. Dobson F. et al. [29] reported that gait type coincidence in patients with cerebral palsy according to clinical examination and CGA was only $22 \%$ (4 cases out of 18), and only joint movements in the sagittal plane were clinically evaluated, without quantification of the range of deviations [30]. Gómez- 
Pérez C. et al. also note that the most sensitive gait parameters relate to the temporal series of joint angles in the sagittal plane compared to the kinetic and superficial electromyography parameters [31]. An algorithm has been proposed for examining patients with complex gait disorders [32]. This algorithm includes three stages: identification of gait deviations, their correlation with clinical disorders and selection of the optimal treatment. Clinical detection of gait abnormalities in patients with cerebral palsy presents the greatest difficulties in this algorithm. Computer instrumental examination of the walking function is the best way to diagnose pathological gait patterns. In addition to clinical examination, it identifies ten to $40 \%$ of previously undetected cases.

Our studies also show that the main value and function of computer-based gait analysis is to identify and quantify persistent disorders of gait kinematics that form pathological patterns. Once these disorders have been identified, a repeated orthopedic examination enables to accurately determine the causes of such disorders (muscle retraction, subluxation in the joints, bone deformities) and choose the surgical methods for their correction.

\section{CONCLUSION}

Positive correlation of the pathological elements of the locomotor profile identified by video gait analysis and clinical examination averaged $66.7 \%$. The lowest error rate was found by assessing the limitation of the range of motion in the ankle and hip joints, 82.6 and $81.8 \%$ of the positive result, respectively.

Muscle retraction is the main (primary) clinical sign leading to positional kinematic deviations in joints and segments. Restricted range of motion in the knee and ankle joints due to muscle retraction causes secondary contractures of these joints

The article is a part of the research on "Development of a model of a personalized rehabilitation complex for early functional rehabilitation of patients with cerebral palsy" of the state assignment for scientific research and development at the FSBI RISC for RTO of the Ministry of Health of Russia.

\section{REFERENCES}

1. Leonchuk S.S., Chibirov G.M., Popkov D.A. Korrektsiia deformatsii stopy po metodike Evans u rebenka s DTsP v ramkakh odnomomentnogo mnogourovnevogo ortopedicheskogo vmeshatelstva. Sluchai iz praktiki [Foot deformity correction according to Evans technique in a child with cerebral palsy within performing the acute multilevel orthopedic intervention. A case report]. Genij Ortopedii, 2016, no. 3, pp. 77-83. (in Russian) DOI: 10.18019/1028-4427-2016-3-77-83.

2. Sarathy K., Doshi C., Aroojis A. Clinical Examination of Children with Cerebral Palsy. Indian J. Orthop., 2019, vol. 53, no. 1, pp. 35-44. DOI: 10.4103/ortho.IJOrtho_409_17.

3. Tugui R.D., Antonescu D. Cerebral palsy gait, clinical importance. Maedica (Buchar), 2013, vol. 8, no. 4, pp. 388-393.

4. Armand S., Decoulon G., Bonnefoy-Mazure A. Gait analysis in children with cerebral palsy. EFORT Open Rev., 2016, vol. 1, no. 12 , pp. 448-460. DOI: 10.1302/2058-5241.1.000052.

5. Borzikov V.V., Rukina N.N., Vorobeva O.V., Kuznetsov A.N., Belova A.N. Videoanaliz dvizhenii cheloveka v klinicheskoi praktike(obzor) [Video analysis of human movements in clinical practice (review)]. Sovremennye Tekhnologii v Meditsine, 2015, vol.7, no. 4, pp. 201-210. (in Russian) DOI: http://doi.org/10.17691/stm2015.7.4.26.

6. Gage J.R. Gait analysis. An essential tool in the treatment of cerebral palsy. Clin. Orthop. Relat. Res., 1993, no. 288, pp. 126-134.

7. Sung K.H., Kwon S.S., Chung C.Y., Lee K.M., Cho G.H., Park M.S. Long-term outcomes over 10 years after femoral derotation osteotomy in ambulatory children with cerebral palsy. Gait Posture, 2018, vol. 64, pp. 119-125. DOI: 10.1016/j.gaitpost.2018.06.003.

8. DeLuca P.A. Gait analysis in the treatment of the ambulatory child with cerebral palsy. Clin. Orthop. Relat. Res., 1991, no. 264, pp. 65-75.

9. Gage J. R. The role of gait analysis in the treatment of cerebral palsy. J. Pediatr. Orthop., 1994, vol. 14, no. 6, pp. $701-702$.

10.Palisano R., Rosenbaum P., Walter S., Russell D., Wood E., Galuppi B. Development and reliability of a system to classify gross motor function in children with cerebral palsy. Dev. Med. Child. Neurol., 1997, vol. 39, no. 4, pp. 214-223.

11.Leardini A., Sawacha Z., Paolini G., Ingrosso S., Nativo R., Benedetti M.G. A new anatomically based protocol for gait analysis in children. Gait Posture, 2007, vol. 26, no. 4, pp. 560-571. DOI: 10.1016/j.gaitpost.2006.12.018.

12.Aksenov A.Yu., Heath G.H., Klishkovskaya T.A., Dolganova T.I. Metodologiia videoanaliza v diagnostike narushenii lokomotornoi funktsii u detei s tserebralnym paralichom pri ispolzovanii ogranichennogo chisla svetootrazhaiushchikh kamer (obzor literatury) [Optimising video-based data capture for pathological gait analysis in children with cerebral palsy using a limited number of retroreflective cameras (literature review)]. Genij Ortopedii, 2019, vol. 25, no. 1, pp. 102-110. (in Russian) DOI 10.18019/1028-44272019-25-1-102-110.

13.Winters T.F., Gage J.R., Hicks R. Gait patterns in spastic hemiplegia in children and young adults. J. Bone Joint Surg. Am., 1987, vol. 69 , no. 3, pp. 437-441.

14.Nieuwenhuys A., Õunpuu S., Van Campenhout A., Theologis T., De Cat J., Stout J., Molenaers G., De Laet T., Desloovere K. Identification of joint patterns during gait in children with cerebral palsy: a Delphi consensus study. Dev. Med. Child. Neurol., 2016, vol. 58, no. 3, pp. 306-313. DOI: 10.1111/dmcn.12892. 
15.Chambers H. The Delphi consensus technique: oracle of gait analysis. Dev. Med. Child. Neurol., 2016, vol. 58, no. 3, pp. 228. DOI: $10.1111 / \mathrm{dmcn} .12954$.

16.Lamberts R.P., Burger M., Du Toit J., Langerak N.G. A Systematic Review of the Effects of Single-Event Multilevel Surgery on Gait Parameters in Children with Spastic Cerebral Palsy. PLoS One, 2016, vol. 11, no. 10, pp. e0164686. DOI: 10.1371/journal. pone.0164686.

17.Rethlefsen S.A., Blumstein G., Kay R.M., Dorey F., Wren T.A. Prevalence of specific gait abnormalities in children with cerebral palsy revisited: influence of age, prior surgery, and Gross Motor Function Classification System level. Dev. Med. Child. Neurol., 2017, vol. 59, no. 1, pp. 79-88. DOI: 10.1111/dmcn.13205.

18.McMulkin M.L., Gordon A.B., Caskey P.M., Tompkins B.J., Baird G.O. Outcomes of Orthopaedic Surgery With and Without an External Femoral Derotational Osteotomy in Children With Cerebral Palsy. J. Pediatr. Orthop., 2016, vol. 36, no. 4, pp. $382-386$. DOI: 10.1097/BPO.0000000000000465.

19.Lofterød B., Terjesen T. Results of treatment when orthopaedic surgeons follow gait-analysis recommendations in children with CP. Dev. Med. Child. Neurol., 2008, vol. 50, no. 7, pp. 503-509. DOI: 10.1111/j.1469-8749.2008.03018.x.

20.Kay R.M., Dennis S., Rethlefsen S., Reynolds R.A., Skaggs D.L., Tolo V.T. The effect of preoperative gait analysis on orthopaedic decision making. Clin. Orthop. Relat. Res., 2000, no. 372, pp. 217-222.

21.Cook R.E., Schneider I., Hazlewood M.E., Hillman S.J., Robb J.E. Gait analysis alters decision-making in cerebral palsy. J. Pediatr. Orthop., 2003, vol. 23, no. 3, pp. 292-295.

22.Skaaret I., Steen H., Terjesen T., Holm I. Impact of ankle-foot orthoses on gait 1 year after lower limb surgery in children with bilateral cerebral palsy. Prosthet. Orthot. Int., 2019, vol. 43, no. 1, pp. 12-20. DOI: 10.1177/0309364618791615.

23.Blumetti F.C., Wu J.C.N., Barzi F., Axt M.W., Waugh M.C., Selber P. Orthopaedic Surgery in Dystonic Cerebral Palsy. J. Pediatr. Orthop., 2019, vol. 39, no. 4, pp. 209-216. DOI: 10.1097/BPO.0000000000000919.

24.Lofterød B., Terjesen T. Changes in lower limb rotation after soft tissue surgery in spastic diplegia. Acta Orthop., 2010, vol. 81, no. 2, pp. 245-249. DOI: 10.3109/17453671003587135.

25.Tomov A.D., Diachkov K.A., Popkov D.A. Kliniko-rentgenologicheskie rezultaty mnogourovnevykh operativnykh vmeshatelstv pri podvyvikhe I vyvikhe bedra u detei s DTsP [Clinical and radiographic results of multilevel surgical interventions for hip subluxation and dislocation in children with cerebral palsy]. Genij Ortopedii, 2018, vol. 24, no. 1, pp. 24-32. (in Russian) DOI 10.18019/10284427-2018-24-1-24-32.

26.Nieuwenhuys A., Papageorgiou E., Molenaers G., Monari D., De Laet T., Desloovere K. Inter- and intrarater clinician agreement on joint motion patterns during gait in children with cerebral palsy. Dev. Med. Child. Neurol., 2017, vol. 59, no. 7, pp. 750-755. DOI: $10.1111 / \mathrm{dmcn} .13404$.

27.Rodda J.M., Graham H.K., Carson L., Galea M.P., Wolfe R. Sagittal gait patterns in spastic diplegia. J. Bone Joint Surg. Br., 2004, vol. 86, no. 2, pp. 251-258.

28.Stott N.S., Atherton W.G., Mackey A.H., Galley I.J., Nicol R.O., Walsh S.J. The reliability and validity of assessment of sagittal plane deviations in children who have spastic diplegia. Arch. Phys. Med. Rehabil., 2005, vol. 86, no. 12, pp. 2337-2341.

29.Dobson F., Morris M.E., Baker R., Wolfe R., Graham H. Clinician agreement on gait pattern ratings in children with spastic hemiplegia. Dev. Med. Child. Neurol., 2006, vol. 48, no. 6, pp. 429-435.

30.Dobson F., Morris M.E., Baker R., Graham H.K. Gait classification in children with cerebral palsy: a systematic review. Gait Posture, 2007, vol. 25, no. 1, pp. 140-152.

31.Gómez-Pérez C., Font-Llagunes J.M., Martori J.C., Vidal Samsó J. Gait parameters in children with bilateral spastic cerebral palsy: a systematic review of randomized controlled trials. Dev. Med. Child. Neurol., 2019, vol. 61, no. 7, pp. 770-782. DOI: 10.1111/ dmcn.14108.

32.Moissenet M., Armand S. Qualitative and quantitative methods of assessing gait disorders. In: Canavese F., Deslandes J., eds. Orthopedic management of children with cerebral palsy: A comprehensive approach. New York, Nova Science, 2015, pp. 215-239.

Received: 03.07.2019

\section{CInformation about the authors:}

1. Georgy M. Chibirov, M.D., Ph.D., Russian Ilizarov Scientific Centre for Restorative Traumatology and Orthopaedics, Kurgan, Russian Federation, Email: georgii_chibirov@mail.ru

2. Tamara I. Dolganova, M.D., Ph.D., Russian Ilizarov Scientific Center for Restorative Traumatology and Orthopaedics, Kurgan, Russian Federation, Email: rjik532007@rambler.ru

3. Dmitrii V. Dolganov, Ph.D. of Biological Sciences,

Russian Ilizarov Scientific Center for Restorative Traumatology and Orthopaedics, Kurgan, Russian Federation, Email: Paradigma-DV@rambler.ru

4.Dmitry A. Popkov, M.D., Ph.D., Professor of RAS, correspondent member French Academy of Medical Sciences, Russian Ilizarov Scientific Centre for Restorative Traumatology and Orthopaedics, Kurgan, Russian Federation, Email:dpopkov@mail.ru 